\title{
Material climate monitoring in wooden buildings in sub-Alpine environments in Slovenia
}

\author{
Miha Humar ${ }^{\mathrm{a}, *}$, Boštjan Lesar ${ }^{\mathrm{a}}$, Davor Kržišnik ${ }^{\mathrm{a}}$ \\ a University of Ljubljana, Biotechnical Faculty, Ljubljana, Slovenia
}

\begin{abstract}
Wood is one of the most important construction materials and its use in building applications has further expanded in recent decades. In order to enable even more extensive and reliable use of wood in outdoor applications, factors affecting wood's service life need to be understood. It is well known that fungal degradation of wood is predominantly affected by temperature (T) and moisture content (MC). In order to elucidate the influence of these two factors, long term monitoring of T, relative humidity (RH) and MC at six locations was carried out: a model house made of thermally modified wood in Mozirje (1), the WWII partisan hospital Franja (2), a traditional hayrack in Pokljuka (3), a house in the north of Slovenia in Vrba (4), building for bird watching in Koper (5) and recently build building in Ljubljana (6). The results clearly showed that fungal degradation of wood is influenced by MC and T. In addition, the influence of micro-climatic conditions on fungal decay can be shown.
\end{abstract}

Peer-review under the responsibility of the organizing committee of the ICMB21.

Keywords: water; moisture; service life; degradation; buildings; wood decay fungi

\begin{tabular}{|ll|}
\hline Nomenclature \\
$\mathrm{MC}$ & wood moisture content \\
$\mathrm{RH}$ & relative humidity \\
$\mathrm{T}$ & temperature \\
\hline
\end{tabular}

\section{Introduction/Background}

Hygrothermal measurements in test houses or real buildings have long been used to address building performance at full-scale in a real environment [1]. These monitoring were performed on various type of buildings, from wooden [2] to buildings made of straw [3]. Field measurements are useful primarily because they expose building components to the whole range of exposure conditions, that cannot be simulated in laboratory conditions. These data are of considerable importance. They can be used to validate the models and to correlate these data with service life data of wood.

The service life of wooden structures is one of the most important pieces of information for the selection of the appropriate construction or façade material. The time during which a particular wooden structure will perform its task depends on a variety of factors [4]. However, the service life of wood exposed outdoors is predominantly affected by wood decaying fungi (brown and white rot fungi) [5]. In addition to a material's inherent durability, the moisture conditions and temperature (T) are the most important factors influencing the ability of fungi to degrade wood [6]. These two factors are influenced by the design of the construction, exposure conditions and local climatic conditions (micro-climate). If moisture content (MC) and T are monitored, the severity of a particular location can be evaluated [2]. Based on the severity of the location, additional protection can be applied with design measures. However, if this is not sufficient, a more durable material should be selected. Durable materials can be chosen from the group of naturally durable wood species, wood species treated with biocides or modified wood [7]. . The aim of the present study was to determine the material climate, as defined by Brischke and co-workers [8], of wooden constructions of six different objects located in the sub-Alpine region at micro-locations with notably different micro-climates.

Monitoring was performed on six objects located in different locations with distinctive micro-climates (Figure 1): a model house made of thermally modified wood in Mozirje (1), the WWII partisan hospital Franja (2), a traditional hayrack in Pokljuka (3), a house in the north of Slovenia in Vrba (4). All of the objects are fairly close together from a geographical perspective. The longest distance between them is less than $100 \mathrm{~km}$. Monitoring started between 2014 and 2016. Three types of continuous monitoring were performed on all of the objects. T sensors Scanntronik (Mugrauer GmbH) were located close to the actual moisture measurement sensors in order to obtain exact values for conversion of electrical conductivity into wood MC [9]. MC and $\mathrm{T}$ data were collected twice per day, at midnight and noon with Thermofox data loggers (Scanntronik Mugrauer GmbH, Germany). Most of the MC sensors were positioned $20 \mathrm{~mm}$ below surface, while temperature was monitored on the surface not to interfere with MC. This equipment enables accurate wood MC measurements between $6 \%$ and $60 \%$. MC was logged twice per day, at midnight and noon, at the same time as temperature. In order to transfer electrical resistance measured inside the wood, wood

\footnotetext{
* Corresponding author.+386 31843 724; Miha.humar@bf.uni-lj.si
} 


\section{ICMB21}

species-specific resistance characteristics were developed based on the methodology described by Otten et al. [9]. Use classes of wood were determined according to EN 335 [10]. The results were periodically downloaded to a personal computer and analysed with Scanntronik software SoftFOX and MS Excel. In addition, temperature and RH data were recorded hourly with a Thermofox hydrofox. Finally, a dose-response model for the fungal decay of wood in aboveground situations, was applied to the recorded material climatic data (MC, T). For comparative analysis, the total dose D (cumulated daily dose over time) was determined [11].

Figure 1. Average moisture content of spruce wood at the objects. Curves are displayed as moving averages of 20 values.Average relative humidity at the objects. Curves are displayed as moving averages of 20 values. Only overlap exposure period is displayed.
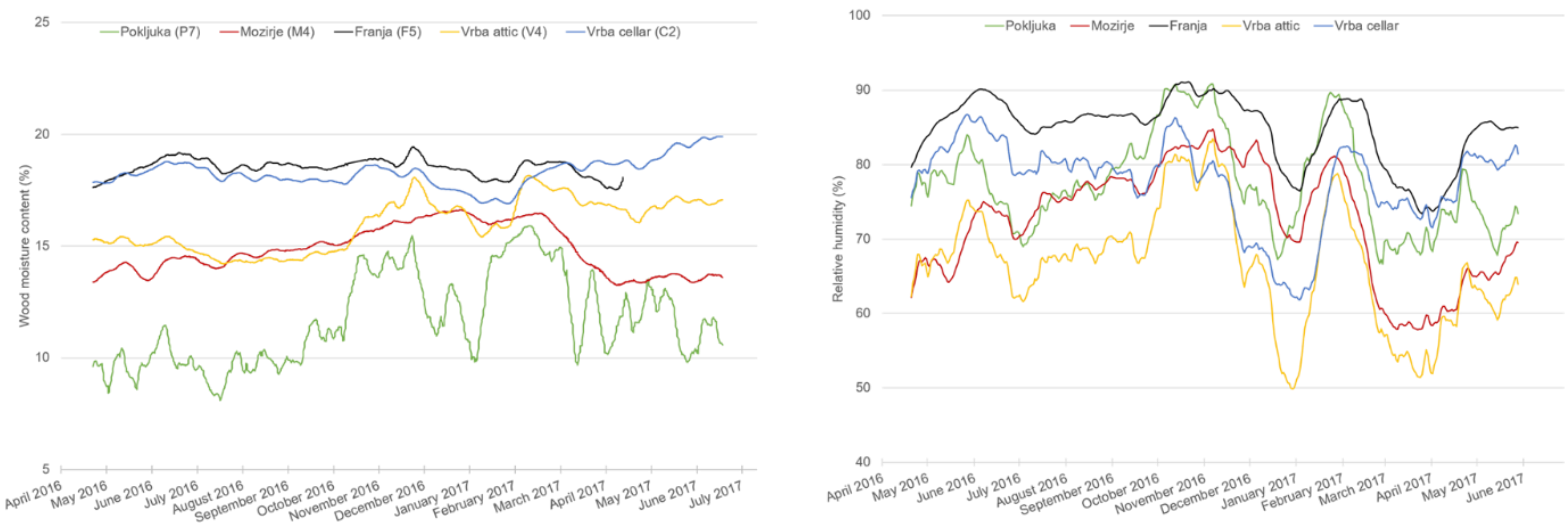

Moisture monitoring was found a very useful method for evaluating different mircoclimatic environment in monitored buildings. There were quite significant variations among the different micro-climates and material climates determined over a fairly short distance. Different thresholds were taken into account. In general, a $25 \%$ threshold limit was considered to be the MC required for fungal decay on untreated wood. The days when this threshold was increased are considered to be wet days. The literature data states a critical period of around 325 days with favourable conditions for fungal decay [12]. This means that the first visible signs of decay develop after approximately 325 days during which the MC exceeds $25 \%$. Our data confirm this theory. In material in which the MC did not exceed the $20 \%$ limit, decay was not found. The results clearly showed that fungal degradation of wood is influenced by MC and T. A model to predict brown and white/soft rot decay of wood was applied to predict the expected service lives of different building components of the respective buildings. The predicted times until onset of decay were well in accordance with findings made during visual assessments and drill resistance measurements at respective sites. The monitoring concept in combination with a mathematical decay prediction model can provide accurate data and valuable guidance for building modern structures and maintaining the wooden buildings. Moisture monitoring of valuable buildings and monuments might also serve as an early warning system but, as shown in the case of Franja hospital, the reliability of a monitoring concept strongly depends on the number of sensors. The positioning of sensors and interpretation of the collected data requires detailed knowledge of timber engineering and wood pathology. Application of the model can be seen on Franja hospital case study[11].

\section{References}

[1] J. Straube, D. Onysko, C. Schumacher, Methodology and Design of Field Experiments for Monitoring the Hygrothermal Performance of Wood Frame Enclosures, Journal of Building Physics. 26 (2002) 123-151. https://doi.org/10.1177/0075424202026002098.

[2] R.C. Welzbacher, C. Brischke, A.O. Rapp, S. Koch, S. Hofer, Performance of Thermally modified timber (TMT) in outdoor application - durability, abrasion and optical appearance, Drvna Industrija. 60 (2009) 75-82. https://doi.org/10.15488/2011.

[3] S. Goodhew, R. Griffiths, T. Woolley, An investigation of the moisture content in the walls of a straw-bale building, Building and Environment. 39 (2004) 1443-1451. https://doi.org/10.1016/j.buildenv.2004.04.003.

[4] T. Isaksson, S. Thelandersson, Experimental investigation on the effect of detail design on wood moisture content in outdoor above ground applications, Building and Environment. 59 (2013) 239-249. https://doi.org/10.1016/j.buildenv.2012.08.023.

[5] O. Schmidt, Wood and tree fungi: Biology, damage, protection, and use, Springer-Verlag Berlin Heidelberg, 2006. https://doi.org/10.1007/3-54032139-X.

[6] J. Van Acker, J. Van den Bulcke, I. De Windt, S. Colpaert, W. Li, Moisture dynamics of modified wood and the relevance towards decay resistance, in: 8th European Conference on Wood Modification (ECWM8), Helsinki, Finland, 2015: pp. 44-55.

[7] M. Kutnik, E. Suttie, C. Brischke, European standards on durability and performance of wood and wood-based products - Trends and challenges, Wood Material Science and Engineering. 9 (2014) 122-133. https://doi.org/10.1080/17480272.2014.894574.

[8] C. Brischke, A.O. Rapp, R. Bayerbach, N. Morsing, P. Fynholm, C.R. Welzbacher, Monitoring the "material climate" of wood to predict the potential for decay: Results from in situ measurements on buildings, Building and Environment. 43 (2008) 1575-1582. https://doi.org/10.1016/j.buildenv.2007.10.001.

[9] K.A. Otten, C. Brischke, C. Meyer, Material moisture content of wood and cement mortars - Electrical resistance-based measurements in the high ohmic range, Construction and Building Materials. 153 (2017) 640-646. https://doi.org/10.1016/j.conbuildmat.2017.07.090.

[10] CEN, European standard EN 335, Durability of wood and wood-based products - Use classes: definitions, application to solid wood and wood-based products, 2013.

[11] D. Kržišnik, C. Brischke, B. Lesar, N. Thaler, M. Humar, Performance of wood in the Franja partisan hospital, Wood Material Science and Engineering. 14 (2019) 24-32. https://doi.org/10.1080/17480272.2018.1438512.

[12] T. Isaksson, C. Brischke, S. Thelandersson, Development of decay performance models for outdoor timber structures, Materials and Structures/Materiaux et Constructions. 46 (2013) 1209-1225. https://doi.org/10.1617/s11527-012-9965-4. 